(2) Open Access Full Text Article

ORIGINALRESEARCH

\title{
Assessing the Readability of Medicine Information Materials: The Case of Tikur Anbessa Specialized Hospital - Mixed Approach
}

This article was published in the following Dove Press journal: Patient Preference and Adherence

\section{Chachu Genale \\ Arebu Issa \\ Bezawit Negash (1D) \\ Kebede Wondu}

Department of Pharmaceutics and Social Pharmacy, School of Pharmacy, College of Health Sciences, Addis Ababa University, Addis Ababa, Ethiopia
Correspondence: Kebede Wondu Department of Pharmaceutics and Social Pharmacy, School of Pharmacy, College of Health Sciences, Addis Ababa University, P.O. Box 1 176, Addis Ababa, Ethiopia Email kebede.wondu@aau.edu.et
Background: Patients are frequently provided with medicine information materials (MIMs). Rendering medicine information through written material is a reliable method. Readability is an important attribute of written material that can affect the reader's ability to comprehend. Patient's perception can also affect the comprehensibility of written MIMs.

Objective: The objectives of the study were to assess the readability of medicine information in Tikur Anbessa Specialized Hospital (TASH); and assessing patients' perception and understanding of medicine information materials.

Methods: This was a cross-sectional study conducted from September 21, 2019 to November 24, 2020, at TASH. Quantitative and qualitative data collection approaches were used in this research. The readability value of each material was determined in accordance with the Flesch Reading ease scores (FRE) and Flesch-Kincaid Grade Level (FKGL). The tools compute readability based on an average number of syllables per word and an average number of words per sentence. FRE provides scores from 0 to 100; higher scores mean easily comprehensible while FKGL sets grade levels for written texts. A structured interview was administered with questions about how MIMs had been used, and was analyzed qualitatively.

Results: The results of this research showed low readability scores of MIMs found in TASH. Most patients do not get MIMs and are unaware of how to use them. They are interested to receive and read medicines information from pharmacists and physicians. Moreover, most of them preferred information through both verbal and written forms.

Conclusion: The readability levels of selected MIMs obtained from TASH are found to be not compliant with the patients' needs. This might be worsening their health outcomes and resulting in poorer use of healthcare services.

Keywords: Flesch readability formula, information, medicine, readability, reading grade level, Tikur Anbessa Specialized Hospital

\section{Introduction}

One aspect that affects the level of comprehension of written material is, in general, the level of literacy of the community. ${ }^{1}$ Literacy is the ability to identify, understand, interpret, create, communicate and compute, using printed and written materials associated with varying contexts. ${ }^{2}$

General literacy, acquaintance with the healthcare system, and the method of health information provision influence health literacy and predict an individual's health status. ${ }^{3}$ Health literacy is defined as the capacity to "acquire, process and comprehend basic health information and services needed to make appropriate health 
decisions." It is regarded as the single best forecaster of an individual's health status. Good environments that enhance health literacy help patients to easily obtain services provided by the healthcare system. ${ }^{5}$

Thus, the health sector has the responsibility to provide appropriate information to patients in various ways; one of which is written materials. ${ }^{6}$ Written medicine information materials are printed materials providing information for individuals who seek health-related knowledge. These could be leaflets, brochures, flyers, clinical practice guidelines, journal articles, or magazines. The most commonly used medicine information source as consulted by patients is the package leaflet which is defined as "a leaflet containing information for the user which accompanies the medicinal product." These complement and reinforce the information provided by healthcare professionals. ${ }^{1}$ The readability of these materials should be grade-appropriate, since understanding them may influence treatment decisions and potentially, patient health outcomes. ${ }^{7}$

Readability is defined as "the simplicity with which written materials are read." It is the extent to which each sentence reads naturally, while comprehensibility is the extent to which the text as a whole is easy to understand. ${ }^{8,9}$ Regarding the patients' point of view, patients usually do not find the written information within their medication package inserts and the language used is not readable for them. And some of the patients are not aware of the use of medicine information materials. ${ }^{10}$ Dispensing leaflets with all medicines and an adequate level of medicine information is a legal requirement in many countries. ${ }^{11,12}$

Rendering health information through written materials is a reliable method. ${ }^{5,13}$ The medical information on medical materials is one of the sources of information for healthcare providers, patients, and other persons. Only addressing medicine information materials are not enough for appropriate information delivery, readability matters. ${ }^{13}$ In order to deliver an accurate message to the readers, the readability level of written information should be evaluated to check whether it fits the reader's ability to read, and is easy to understand. Although effective communication lowers patients' anxiety, and improves compliance and clinical outcome, poor communication between healthcare providers and patients can lead to the medical malpractice cases. ${ }^{5,13}$

In Ethiopia, patient dissatisfaction with the amount and quality of medicines information has often been reported. ${ }^{14,15}$ Beyond that report, no further results have been published about the readability, patients' perception, and understanding of the medicine information materials in Ethiopia. Therefore, this study aimed to assess the readability, patients' perception, and understanding of the medicine information materials (MIMs) in Tikur Anbessa Specialized Hospital (TASH), Addis Ababa, Ethiopia.

\section{Methods}

\section{Study Setting, Design and Period}

The study was conducted in Tikur Anbessa Specialized Hospital (TASH). TASH is the largest teaching hospital under the administration of Addis Ababa University in Ethiopia. The hospital was established in 1972 and has more than 800 beds providing treatment services for about half a million patients per year. The hospital pharmacy service is one of the services given under TASH which is organized as a directorate. The hospital pharmacy directorate consists of outpatient pharmacy unit, inpatient pharmacy unit, emergency pharmacy unit, oncology pharmacy unit, drug information center, pharmaceutical supply management unit, and clinical pharmacy unit. We conducted a cross-sectional study at the outpatient and inpatient pharmacy units of TASH using qualitative and quantitative data collection methods. For quantitative method, MIMs were collected by using stratified sampling method from each pharmacy unit. After classifying each into local and imported, altogether 14 local and 22 imported, and 15 local and 22 imported leaflets, from inpatient and outpatient pharmacy units, respectively, were picked up. For qualitative sampling, a purposive sampling method was used with saturation point up to 13 participants and 2 additional participants interviewed to confirm that saturation point (participant at who flows of idea become similar with the previous ones) is reached. The content of the interviewer administered questionnaire were demographics of the participants, access, importance, utility, adequacy, and understandability of the medicine information materials; as well as support. The study was conducted from September 21, 2019 to November 24, 2020.

\section{Source and Study Population}

The source population was all MIMs available in TASH, and patients who have been attending to the different departments of the hospital. The study population was MIMs available in the outpatient and inpatient pharmacy 
units; and patients visiting the same pharmacy units of TASH during the study period.

\section{Eligibility Criteria}

Inclusion

Printed MIMs available in TASH were included in the study. Volunteer pharmacy clients aged above 18 (eligible for consent) were included.

\section{Exclusion}

Medicine information materials written in local language were excluded since they are insignificant in number and also as there is no readability tool adapted to local languages in the country. Also, those patients whose age is below 18 years were excluded from the study.

\section{Data Collection Procedures}

The MIMs were collected by contacting selected pharmacy units of TASH. Patients were interviewed as they collected their prescriptions and medications. A structured interview was conducted with questions about how medicine information materials had been used. It was translated to Amharic language and translated back to English, then the interviews were performed in Amharic at the respective pharmacy units of respondents by the principal investigator (PI) and all interviews were recorded and notes were taken. After written informed consent obtained, face to face interview of 15 participants was conducted for an average of 20 minutes.

\section{Description of Variables}

The texts in our study have as independent variables total number of syllables, words, and sentences.

\section{Definitions by Oxford Dictionary Syllable}

Noun. A unit of pronunciation having one vowel sound, with or without surrounding consonants, forming the whole or a part of a word; for example, there are two syllables in water and three in inferno.

\section{Word}

Noun [countable] a single unit of language that means something and can be spoken or written.

\section{Sentence}

Noun. A set of words that is complete in itself, typically containing a subject and predicate, conveying a statement, question, exclamation, or command, and consisting of a main clause and sometimes one or more subordinate clauses.

The main variables in our study are dependent variables, these are the readability scores of two tools, namely FRE and FKGL. Both scores depend on the total number of syllables, words and sentences that are found in a given text.

\section{The FRE Formula ${ }^{16}$}

$\mathrm{FRE}=206.835-(1.015 \times \mathrm{ASL})-(84.6 \times \mathrm{ASW})$

FRE $=$ Flesch Readability Ease

ASL $=$ Average Sentence Length (i.e., Total words $\div$ Total sentences)

ASW $=$ Average number of syllables per word (i.e., Total syllables $\div$ Total words)

The second and important score is the F-K grade level: $\mathrm{FKGL}=(0.39 \times \mathrm{ASL})+(11.8 \times \mathrm{ASW})-15.59$

\section{Data Quality Management}

Data quality was ensured through checking the collected materials whether they are intended for patient education. The readability was assessed by two different individuals. For the qualitative sampling, peer to peer review was conducted for the translation of the questionnaire. Then the collected data were checked for completeness and correctness. Finally, data cleaning was performed.

\section{Data Analysis}

The readability values were determined in accordance with the Flesch readability ease score (FRE) and FleschKincaid grade levels (FKGL) methods. ${ }^{16}$ The collected materials were scanned and converted to word text using a document scanner downloaded from play store. They were checked for grammar and spelling by inserting into Microsoft Word (MS) 2010. Consequently, readability was assessed by enabling readability statistics in MS Word 2010, the results were then analyzed using SPSS version 25. Descriptive statistics such as mean, median and standard deviation were used to present the data. Besides, the qualitative data were analyzed by using thematic analysis. $^{17}$

\section{Ethical Consideration}

This study was approved by the Institutional Review Board of School of Pharmacy, Addis Ababa University. Confidentiality and privacy of the data were guaranteed during the data collection period. The patients' name and address were not documented during interview and the collected information was used for research purposes only. 
Furthermore, the study was carried out in accordance with World Medical Association Declaration of Helsinki. ${ }^{18}$

\section{Results}

A total of 73 medicine information leaflets were collected from Tikur Anbessa Specialized Hospital outpatient and inpatient pharmacies and the results assigned as locally manufactured and imported products as follows (Table 1).

The results show that the locally manufactured medicines information materials have slightly greater readability than the imported materials. However, the readability of locally manufactured as well as of the imported medicines information materials is described as very difficult.

The local manufactured medicines information materials, with readability ease score of 28.47 , was identified as very difficult to read. Similarly, the mean FRE score of imported items, 25.44, is also identified as very difficult (Table 2). Larger deviations of readability values from the arithmetic means were established for imported texts in comparison with local texts.

Local and imported leaflets were selected relating to medicines information. After analyzing these texts, grade levels which exceeded the graduates grade level, were established. The values appeared to be very high (Table 2).

\section{Results of Participant's Interview}

A total of 15 clients appearing in the pharmacies were approached. The percentage of the male participants was $60 \%$ and that of female was $40 \%$. Participant's demographic characteristics (age, gender and educational level) are shown in Table 3.

\section{Information}

\section{Access}

The first question was about access to medicine information and the majority of them said they were usually provided with information. Some of the respondents said they sometimes get medicines information.

For instance, a university postgraduate female respondent aged 26 said:

"Sometimes I get information but as I'm a chronic user of these medications I don't need information as much. I talk with the doctor in detail. Sometimes the pharmacist tells me about the administration."

Nearly half of the respondents claimed that they were not provided with medicines information. The reasons varied from respondent to respondent and some are quoted below.
A university postgraduate male client aged 32 claimed:

"I have never got information. May be due to the laziness of the pharmacists."

And other university postgraduate male respondent aged 27 said:

"I didn't get medicines information as they don't have enough time and adequate facilities."

A primary school graduate male client aged 37 said:

"I get medicines information outside this hospital but, I didn't get any in this hospital."

Lastly, a secondary school graduate male client aged 43 claimed that "Medicines information is not provided. There is no human power and even the existing one is not providing information. They only chat with each other."

\section{Materials}

Although there are some differences, almost all of the respondents have fairly similar opinions on the importance of the medicines information materials. Three-quarters of respondents claimed that these materials are important and the remainder said they have no idea.

A university postgraduate male client aged 42 said,

"Of course it's relevant for who could understand its importance; the medicine information materials are very important and give information on different aspects of the drug."

Other participant responded "I have never found leaflets. How do I know its relevance without reading it?"

A secondary school graduate male client aged 57 stated "I never thought of this. I have no idea on this. I just expect from the pharmacy professionals as I thought they know better."

\section{Importance}

Almost all of the respondents have similar opinions on the importance of medicines information and said it is important. A university postgraduate male client aged 30 said, "It's important since it tells dose, side effects and disadvantages."

\section{Adequacy}

It is known that adequacy of information depends on the person's extent of information need. The respondents have enough information and relate the reason why they say the information on the materials is adequate. Some of them relate thing starting from the target of medicines information material preparation. And one respondent replies that she thought it is enough since it is confirmed by science.

A university postgraduate male client aged 29 said: 
Table I Readability of Medicine Information Materials in Tikur Anbessa Specialized Hospital, Addis Ababa, Ethiopia

\begin{tabular}{|c|c|c|c|c|}
\hline $\begin{array}{l}\text { Product } \\
\text { Identification }\end{array}$ & Product and Strength & Language & $\begin{array}{l}\text { Flesch Reading Ease } \\
\text { Score }^{a}\end{array}$ & $\begin{array}{l}\text { Flesch-Kincaid Grade } \\
\text { Level }^{b}\end{array}$ \\
\hline PI (Local) & Paracetamol $125 \mathrm{mg} /$ suppository & English & 46.61 & 11.4 \\
\hline P2 (Local) & Metronidazole $250 \mathrm{mg} /$ tablet & English & 29.75 & 15.9 \\
\hline P3 (Local) & Metoclopramide $5 \mathrm{mg} / 5 \mathrm{~mL}$ syrup & English & 50.57 & 9.82 \\
\hline P4 (Local) & Ketoconazole $200 \mathrm{mg} /$ tablet & English & 24.02 & $|4.5|$ \\
\hline P5 (Local) & Ibuprofen $400 \mathrm{mg} /$ tablet & English & 26.81 & 15.1 \\
\hline P6 (Local) & Amitriptyline $25 \mathrm{mg} /$ tablet & English & 24.27 & 16.03 \\
\hline P7 (Local) & Chloramphenicol $250 \mathrm{mg} /$ tablet & English & 21.94 & 15.9 \\
\hline P8 (Local) & $\begin{array}{l}\text { Sulfamethoxazole + Trimethoprim } 400 \mathrm{mg}+ \\
80 \mathrm{mg} / \text { tablet }\end{array}$ & English & 32.58 & 10.4 \\
\hline P9 (Local) & Aciclovir $400 \mathrm{mg} /$ tablet & English & 36.78 & 12.0 \\
\hline PIO (Local) & Gentamicin $40 \mathrm{mg} / \mathrm{mL}$ injection & English & 38.58 & 15.08 \\
\hline PII (Local) & Folic acid $5 \mathrm{mg} /$ tablet & English & 27.72 & 16.32 \\
\hline PI2 (Local) & Benzathine penicillin $2.4 \mathrm{MIU}$ injection & English & 38.44 & 13.7 \\
\hline PI3 (Local) & Phenobarbitone $100 \mathrm{mg} /$ tablet & English & 19.21 & 16.72 \\
\hline PI4 (Local) & Ciprofloxacin 500 mg/tablet & English & 19.12 & 17.0 \\
\hline PI5 (Local) & Ranitidine $150 \mathrm{mg} /$ tablet & English & 22.12 & 11.9 \\
\hline PI6 (Local) & Amlodipine $10 \mathrm{mg} /$ tablet & English & 38.23 & 9.83 \\
\hline PI7 (Local) & Indometacin $25 \mathrm{mg} /$ capsule & English & 52.3 & 8.4 \\
\hline PI8 (Local) & Paracetamol $120 \mathrm{mg} / 5 \mathrm{~mL}$ suspension & English & 22.3 & 11.4 \\
\hline PI9 (Local) & Carbamazepine $200 \mathrm{mg} /$ tablet & English & 35.05 & 15.9 \\
\hline P20 (Local) & Metformin $\mathrm{HCl} 500 \mathrm{mg} /$ tablet & English & 23.02 & $|4.8|$ \\
\hline P2I (Local) & Enalapril $10 \mathrm{mg} /$ tablet & English & 19.6 & 14.4 \\
\hline P22 (Local) & Fluoxetine $20 \mathrm{mg} /$ capsule & English & 8.8 & 16.7 \\
\hline P23 (Local) & Norfloxacin $400 \mathrm{mg} /$ tablet & English & 14.1 & 14.4 \\
\hline P24 (Local) & Dimenhydrinate $50 \mathrm{mg} / \mathrm{tablet}$ & English & 21.3 & 13.9 \\
\hline P25 (Local) & Furosemide $40 \mathrm{mg} /$ tablet & English & 17.2 & 15.2 \\
\hline P26 (Local) & Albendazole $100 \mathrm{mg} / 5 \mathrm{~mL}$ suspension & English & 18.9 & 14.37 \\
\hline P27 (Local) & Cetirizine $\mathrm{HCl} 10 \mathrm{mg} /$ tablet & English & 22.5 & 15.1 \\
\hline P28 (Local) & Glibenclamide $5 \mathrm{mg} /$ tablet & English & 50.8 & 10.3 \\
\hline P29 (Local) & Omeprazole $20 \mathrm{mg} /$ capsule & English & 23.18 & 15.16 \\
\hline P30 (Imported) & Haloperidol $5 \mathrm{mg} /$ tablet & English & 11.8 & 15.7 \\
\hline P3I (Imported) & Spironolactone $25 \mathrm{mg} /$ tablet & English & 9.9 & 15.9 \\
\hline P32 (Imported) & Vitamin B6 $50 \mathrm{mg} /$ tablet & English & 25.534 & 14.9 \\
\hline P33 (Imported) & Amiodarone $\mathrm{HCL} 150 \mathrm{mg} / 3 \mathrm{~mL}$ injection & English & 18.8 & 14.2 \\
\hline P34 (Imported) & Captopril $25 \mathrm{mg} /$ tablet & English & 20.1 & 15.1 \\
\hline P35 (Imported) & $\begin{array}{l}\text { Albunorm } 20 \%-50 \mathrm{~mL} \text {, Solution for infusion Human } \\
\text { albumin }\end{array}$ & English & 54.6 & 8.5 \\
\hline P36 (Imported) & Xylometazoline $\mathrm{HCl} 0.05 \%$ nasal spray & English & 15.6 & 16.2 \\
\hline P37 (Imported) & Epsitron $25 \mathrm{mg} /$ tablet & English & 23.5 & 16.2 \\
\hline P38 (Imported) & $\begin{array}{l}\text { Bactrim (Trimethoprim (80)/sulfamethoxazole } \\
\text { (400) } \mathrm{mg} / \text { tablet) }\end{array}$ & English & 19.6 & 14.3 \\
\hline P39 (Imported) & Cefixime $400 \mathrm{mg} /$ tablet & English & 23.21 & 12.8 \\
\hline P40 (Imported) & Kenacort $40 \mathrm{mg} / \mathrm{ImL}$ injection & English & 34.08 & 9.01 \\
\hline P4I (Imported) & Hyoscine butylbromide $20 \mathrm{mg} / \mathrm{mL}$ injection & English & 26.66 & $13.0 \mid$ \\
\hline P42 (Imported) & Tetanus antitoxin $3000 \mathrm{IU} / \mathrm{ImL}$ injection & English & 16.94 & $|5.6|$ \\
\hline P43 (Imported) & Pyloocain $0.05 \%$ spray & English & 8.12 & 16.91 \\
\hline P44 (Imported) & Glibenclamide $5 \mathrm{mg} /$ tablet & English & 18.87 & 13.91 \\
\hline P45 (Imported) & Morphine $30 \mathrm{mg} /$ tablet & English & 22.90 & 13.05 \\
\hline P46 (Imported) & Diazepam $5 \mathrm{mg} / 2 \mathrm{~mL}$ injection & English & 20.36 & 14.20 \\
\hline P47 (Imported) & Sodium valproate $200 \mathrm{mg} /$ tablet & English & 27.96 & 13.97 \\
\hline
\end{tabular}

(Continued) 
Table I (Continued).

\begin{tabular}{|c|c|c|c|c|}
\hline $\begin{array}{l}\text { Product } \\
\text { Identification }\end{array}$ & Product and Strength & Language & $\begin{array}{l}\text { Flesch Reading Ease } \\
\text { Score }^{\text {a }}\end{array}$ & $\begin{array}{l}\text { Flesch-Kincaid Grade } \\
\text { Level }^{b}\end{array}$ \\
\hline P48 (Imported) & Clonazepam $2 \mathrm{mg} /$ tablet & English & 49.13 & 9.65 \\
\hline P49 (Imported) & Lorazepam $2 \mathrm{mg} /$ tablet & English & 28.24 & 12.98 \\
\hline P50 (Imported) & Tramadol HCL 100 mg/tablet & English & 28.38 & 14.33 \\
\hline P5I (Imported) & Ciprofloxacin 100 mg/tablet & English & 24.332 & 15.52 \\
\hline P52 (Imported) & Ciprofloxacin 500 mg/tablet & English & 18.36 & 15.91 \\
\hline P53 (Imported) & $\begin{array}{l}\text { Dexamethasone sodium phosphate } 4 \mathrm{mg} / \mathrm{mL} \\
\text { injection }\end{array}$ & English & 26.86 & 14.28 \\
\hline P54 (Imported) & Doxycycline $100 \mathrm{mg} /$ tablet & English & 49.19 & 10.8 \\
\hline P55 (Imported) & Dopamine $\mathrm{HCL} 80 \mathrm{mg} / \mathrm{mL}$ injection & English & 21.98 & 13.94 \\
\hline P56 (Imported) & Ciprofloxacin $0.03 \%$ eye/ear drop & English & 41.98 & 11.37 \\
\hline P57 (Imported) & Hydrocortisone Acetate Cream I\% topical & English & 25.03 & 14.06 \\
\hline P58 (Imported) & Candesartan Cilexetil $8 \mathrm{mg} /$ tablet & English & 52.63 & 9.07 \\
\hline P59 (Imported) & Thioridazine HCL 25 mg/tablet & English & 13.287 & $15.7 \mid$ \\
\hline P60 (Imported) & Ergotamine tartare I mg \& Caffeine $100 \mathrm{mg} /$ tablet & English & 16.86 & 14.09 \\
\hline P6I (Imported) & Bisacodyl $10 \mathrm{mg} / \mathrm{suppository}$ & English & 14.10 & 15.38 \\
\hline P62 (Imported) & Atorvastatin calcium trihydrate $10 \mathrm{mg} /$ tablet & English & 19.374 & 16.5 \\
\hline P63 (Imported) & Acetylsalycilic acid $81 \mathrm{mg} /$ tablet & English & 32.965 & 12.91 \\
\hline P64 (Imported) & Erythromycin $250 \mathrm{mg} /$ tablet & English & 20.514 & 12.91 \\
\hline P65 (Imported) & Diclofenac $50 \mathrm{mg} /$ tablet & English & 35.629 & 11.39 \\
\hline P66 (Imported) & Phytomenadione $10 \mathrm{mg} / \mathrm{ImL}$ injection & English & 12.6 & 15.6 \\
\hline P67 (Imported) & Atenolol $50 \mathrm{mg} /$ tablet & English & 8.5 & 17.1 \\
\hline P68 (Imported) & Thyroxine sodium $50 \mathrm{mcg} /$ tablet & English & 19.38 & 15.93 \\
\hline P69 (Imported) & Miconazole nitrate $10 \mathrm{mg} /$ tablet & English & 42.53 & 9.70 \\
\hline P70 (Imported) & Tropicamide ophthalmic solution I\% eye drop & English & 22.44 & 13.28 \\
\hline P7I (Imported) & $\begin{array}{l}\text { Amoxicillin and clavulanate potassium } 625 \mathrm{mg} / \\
\text { tablet }\end{array}$ & English & 32.17 & 13.92 \\
\hline P72 (Imported) & Leucovorin calcium $350 \mathrm{mg} / \mathrm{vial}$ injection & English & 48.3 & 11.0 \\
\hline P73 (Imported) & Atracurium besylate $10 \mathrm{mg} / \mathrm{mL}$ injection & English & 16.1 & 17.8 \\
\hline
\end{tabular}

Notes: ${ }^{a}$ FRE Score: 0-30: Very difficult; 30-50: Difficult; 50-60: Fairly difficult; 60-70: Standard; 70-80: Fairly easy; 80-90: Easy; 90-100: Very easy. ${ }^{16}$ blesch-Kincaid Grade Level: Rates text on a US school grade level. A score of 8.0 means that an eighth grader can understand the document. ${ }^{19,20}$

Table 2 Statistical Analysis Results for Calculated Flesch Reading Ease Scores and Flesch-Kincaid Grade Level in Tikur Anbessa Specialized Hospital, Addis Ababa, Ethiopia

\begin{tabular}{|l|l|l|l|l|l|l|}
\hline \multirow{2}{*}{ Parameter } & \multicolumn{2}{|c|}{ Mean \pm SD } & \multicolumn{2}{c|}{ Minimum } & \multicolumn{2}{c|}{ Maximum } \\
\cline { 2 - 7 } & Local (n=29) & Imported (n=44) & Local (n=29) & Imported (n=44) & Local (n=29) & Imported (n=44) \\
\hline Flesch Reading Ease score & $28.47 \pm 11.26$ & $25.44 \pm 11.92$ & 8.8 & 8.12 & 52.3 & 54.6 \\
Flesch-Kincaid Grade Level & $13.85 \pm 2.39$ & $13.78 \pm 2.28$ & 8.4 & 8.5 & 17 & 17.8 \\
\hline
\end{tabular}

"The manufacturers prepararation is enough. If I thought it is not enough, I Google and get what I need." Other respondent with similar level of education said that "It's adequate enough because I don't expect more if it informs the dose and side effects it is enough."

Another younger male client told that information is adequate. "Adequate. I get information I need. Even if the doctor mistakenly writes I review the leaflet and return to doctor."
Some of the participants have no knowledge to decide on the adequacy of information: "I can say nothing on this because it depends on individuals' extent of information need." (Female, illiterate).

In contrary other respondents, one respondent, who is a preparatory graduate, replied "I don't think it is enough. The thing written on it and the practice do not match each other." 
Table 3 Participants' Demographic Characteristics in Tikur Anbessa Specialized Hospital, Addis Ababa, Ethiopia

\begin{tabular}{|l|l|l|l|}
\hline Characteristics & Categories & Number (N) & Percentage \\
\hline Gender & Male & 9 & $60 \%$ \\
& Female & 6 & $40 \%$ \\
\hline \multirow{2}{*}{ Age (years) } & $20-25$ & 3 & $20 \%$ \\
& $26-57$ & 12 & $80 \%$ \\
\hline \multirow{2}{*}{ Education } & Uneducated & 2 & $13 \%$ \\
& Primary & 3 & $20 \%$ \\
& Secondary & 3 & $20 \%$ \\
& Preparatory & 2 & $13 \%$ \\
& University & 5 & $33 \%$ \\
& Postgraduate & & \\
& & \multicolumn{2}{|l}{} \\
\end{tabular}

\section{Characteristics}

Utility

Most of the participants do not read the medicines information leaflets, and their reasons were different. The majority of them claimed a language barrier, being illiterate and unavailability of leaflets. The statement of two primary school graduate clients was "I didn't read because it's written in English and I didn't read because of the language." One client said she do not have a habit of reading leaflets even though she is a university graduate.

Two out of five read the leaflet in order to get information on drugs use, administration, side effects, expiry date, and contraindications.

A preparatory school graduate male patient aged 45 said:

"Yes, I read to know about my drugs deeply. I read about duration of treatment, use, cautions, dose, contraindications and how to store."

In addition, another client said he read leaflets for the purpose of overall information on the drug he collected. "Yes, I read to get enough and overall information concerning the drug I'm going to take." A secondary school graduate female client stated, "I read sometimes when I am having sit, to compare with what I'm being told and get additional information."

\section{Language}

Although there are some differences, the majority of the respondents said the language was difficult to understand and comprehend. The complaints were not being in the local language, and medical and pharmaceutical terminologies. $20 \%$ of participants were using the internet to search for terms they did not understand. A preparatory school graduate male client replied, "It's not easy if not supported with dictionary and internet." Another similar grade level respondent replied, "I selectively read the part I could understand but it's not totally easy. This is because it isn't written in a language I understand."

Other respondents reacted that the language is easier to understand and comprehend.

A university postgraduate male client aged 35 said, "I guess I understand up to $80 \%$ of the written information. I Google pharmaceutical terms as they are difficult for me."

Another university postgraduate also reacted, "It is enough. I Google for medical terminologies if I don't know their meaning."

\section{Package}

Although presence of leaflets within the package is one of the requirements during dispensing, most of the time it may not reach the end user for different reasons. The most common and those responded by most of the study participants are narrated below.

As a secondary school graduate male client said, inserts are mostly provided for only a full pack. "If it is a full pack, usually there is a leaflet within it. But I didn't receive one for strips with no pack."

Other respondent said "Usually I get within the package but sometimes there is no leaflet in some of the pack." While a few responded, "I never get leaflets in my visits to the pharmacy."

\section{Support}

The majority of respondents preferred information provision through both verbal and written materials. The preferred sources of medicines information for most were pharmacists, doctors, nurses, and leaflets. Some of them also use the internet as a source of information. The patients also ask their neighbors, sons, colleagues with similar disease and/or with knowledge of the drug.

A university postgraduate male: "Mainly I ask from the pharmacy and also from the doctor. I also ask a patient with similar disease condition."

A primary school graduate female: "It's better if the pharmacy, doctor and even the institute provide me with information." "Sometimes I ask a neighbor who knows about the drugs I'm using."

A secondary school graduate male:

"First of all pharmacy is my primary source of medicines information and then leaflets. I ask my son or friend who 
is a doctor to read for me otherwise I don't ask other people for drug information but the place where I could get the prescribed drug in case it's not available here."

A university postgraduate female: "I wish I get information on medicines from pharmacy since the doctors don't provide information on it."

\section{Discussion}

The result showed that most locally available medicine information materials are not suitable for the readers. It is obvious that face to face communication with the healthcare provider is effective for healthcare delivery and better patient outcome. However, it is also important not to forget that written medicines information materials can help in assimilating medical awareness in the community, together with verbal counseling. ${ }^{5,13}$ This is because written material could be needed to review after a clinical encounter. Although it's not enough, the country's population literacy especially in the urban areas is making good progress. Health literacy is needed as health is crucial for a better life. Medicines information also helps the patient on how to be involved in enhancing optimal treatment outcome. In this regard, the Food and Drug Administration (FDA) has upheld that providing useful written medicine information to patients is one way to ensure optimal medication use. ${ }^{21}$

For this, it's vital to deliver material that is comprehensible. As the results revealed, only one material has an FRE score of 54.6. The rest are 50 and below. Even the best do not reach the standard (FRE Score ranging from 60 to 70 ) readability score. These findings are in good agreement with the study conducted on readability assessment of online patient education material on congestive heart failure. $^{22}$

Comparing with imported medicines information materials, local ones have a slightly higher FRE score (Table 2). This could be due to the fact that local manufacturers do not prefer to use complex words and long paragraphs that could bore the reader.

Both imported and local materials have almost similar FKGL scores. Thus, both items reveal decreasing values of the readability ease as grade levels are higher than the recommended FKGL for medicines information items. This study has shown inappropriate readability grade levels of texts, which is in agreement with results of a previous study on analyzing readability of medicines information material in Slovenia. ${ }^{7}$ Thus, the MIMs have to be revised for their readability levels. It is better if there are strong institutional policies enforcing manufacturers to prepare written materials meeting end-user needs for ease of readability.

Our qualitative study revealed that most of the interviewed patients do not read the leaflet due to a lack of education, unavailability of the leaflets in the package, lack of habit, and unclear texts of the leaflets. Although it is not totally confirmed, the result set with our hypotheses which were that patients often do not get leaflets within the pack. This can negatively affect the provision of optimal patient information. In order to solve the problems in the case of information delivery, it is advised to give awareness to both health professionals and consumers. Those who do not have an academic education should be trained to participate in healthcare provision through collaborating with those who have a habit of asking for help for medicines information from health professionals and from those who could understand the message on the medicines information materials. Besides, different researchers also suggested the importance of setting regulations that enforce the provision of medicines information materials to patients, as is the case in different countries of Europe. ${ }^{11,12}$

Another most commonly reported reason for not reading the leaflet was lack of habit. Patients with a good habit of reading can participate in health care and alleviate the negative outcomes of poor medication adherence. This reduces the cost of health expenditures and helps the patient to get better treatment with minimal cost. For instance, knowing the problems of antibiotics resistance due to poor medication adherence and preventing this situation from happening halt the cost that will be expended to buy other drugs with more pathogenic coverage.

An additional reason for not reading was the low clarity of the texts in the MIMs. The understandability of the written text of MIMs is also highly dependent on its readability. The readability of written material for a public audience should be a major concern for the writer. Patients may be ashamed of their inadequate literacy level or skills and may never tell anyone that they cannot read or understand medication information. ${ }^{23}$ Moreover; medical terminologies in which MIMs are written are difficult to understand. Thus, we recommend patients ask health care providers about the information of their medications.

This study revealed that patients seek knowledge on drugs they are taking, particularly on drug use, 
administration side effects, expiry date, and contraindications. So, providing materials that fit their appropriate grade level is a very important part of patient education.

It has been hypothesized that generally younger, wealthier, and better-educated individuals are more likely to be involved in activities that promote health. ${ }^{24}$ As self-education about medications is an integral part of ensuring better health, our results agree with this statement with respect to the level of education.

As our study shows, patients' information need is high and most have knowledge of its importance. Adequate information both verbally and in written form should be provided for every patient attending the pharmacy. Since the pharmacist has a professional obligation to counsel, one would expect counseling by the pharmacist to be the primary reason provided by the patients for not reading the leaflet.

The results of this study have several implications for pharmacists and also for other health professionals. Although the leaflet may be an important source of information, a substantial number of patients do not use it or use it only partially. This highlights the importance of adequate verbal counseling in ensuring the proper use of MIMs. Pharmacists should also ensure that the leaflet is personally passed to the patient rather than placed in or attached to the bag.

\section{Limitations}

The interview was conducted by including only a few participants. The authors of this study acknowledged that the results can be extrapolated only to TASH's patients.

\section{Conclusion}

This study used a mixed-method approach to assess the readability of MIMs for TASH's patients. Many MIMs are written at a level that is not suitable for most of the patients. Furthermore, patients do not read the MIMs due to a lack of education, unavailability of the leaflets in the package, lack of habit, and unclear texts of the leaflets. It is unsound to provide MIMs that are written above the target user's education level. Patient counseling should go together with the provision of MIMs and the patient's understanding of the use of these materials is an imperative part of integrating patient and health care providers for better health outcomes.

\section{Acknowledgments}

The authors thank the patients and staff of Tikur Anbessa Specialized Hospital for their contribution and support throughout this study.

\section{Disclosure}

The authors report no conflicts of interest in this work.

\section{References}

1. Piñero-López MÁ, Figueiredo-Escribá C, Modamio P, Lastra CF, Mariño EL. Readability assessment of package leaflets of biosimilars. BMJ Open. 2019;9(1):e024837. doi:10.1136/bmjopen2018-024837

2. Montoya S Defining literacy. UNESCO institute for statistics. Available from: http:/gaml.uis.unesco.org/wp-content/uploads/sites/2/2018/12/4. 6.1_07_4.6-defining-literacy.pdf. Accessed March 17, 2021.

3. Badarudeen S, Sabharwal S. Assessing readability of patient education materials: current role in orthopaedics. Clin Orthop Related Res. 2010;468(10):2572-2580. doi:10.1007/s11999-010-1380-y

4. Baker DW, Parker RM, Williams MV, Clark WS, Nurss J. The relationship of patient reading ability to self-reported health and use of health services. Am J Public Health. 1997;87(6):1027-1030. doi:10.2105/AJPH.87.6.1027

5. Weis BD. "Health Literacy: A Manual for Clinicians". Chicago: American Medical Association, American Medical Foundation; 2003.

6. Grime J, Blenkinsopp A, Raynor DK, Pollock K, Knapp P. The role and value of written information for patients about individual medicines: a systematic review. Health Exp. 2007;10(3):286-298. doi:10.1111/j.1369-7625.2007.00454.x

7. Kasesnik K, Kline M. Analyzing readability of medicines information material in Slovenia. South Med Rev. 2011;4(2):80-87. doi:10. 5655/smr.v4i2.1005

8. Abu-Heija AA, Shatta M, Ajam M, Abu-Heija U, Imran N, Levine D. Quantitative readability assessment of the internal medicine online patient information on Annals. org. Cureus. 2019;11(3):e4184. doi:10.7759/cureus.4184

9. Munsour EE, Awaisu A, Hassali MA, Darwish S, Abdoun E. Readability and comprehensibility of patient information leaflets for antidiabetic medications in Qatar. J Pharm Techn. 2017;33(4):128-136.

10. Gavgani VZ, Mirzadeh-Qasabeh S, Hanaee J, Hamishehkar H. Calculating reading ease score of patient package inserts in Iran. Drug Healthc Patient Saf. 2018;10:9-19. doi:10.2147/DHPS.S150428

11. Pires C, Cavaco A, Vigário M. How sociodemographic features impact subjects' opinion on packages leaflets of medicines? Australasian Med J. 2017;10(9):774-784. doi:10.21767/AMJ.2017. 3110

12. Posch N, Horvath K, Wratschko K, Plath J, Brodnig R, Siebenhofer A. Written patient information materials used in general practices fail to meet acceptable quality standards. BMC Fam Pract. 2020;21(1):1-6. doi:10.1186/s12875-020-1085-6

13. Morony S, Flynn M, McCaffery KJ, Jansen J, Webster AC. Readability of written materials for CKD patients: a systematic review. Am J Kidney Dis. 2015;65(6):842-850. doi:10.1053/j.ajkd.20 14.11.025

14. Ayele Y, Hawulte B, Feto T, Basker GV, Bacha YD. Assessment of patient satisfaction with pharmacy service and associated factors in public hospitals, Eastern Ethiopia. SAGE Open Med. 2020;8:1-7. doi:10.1177/2050312120922659

15. Surur AS, Teni FS, Girmay G, Moges E, Tesfa M, Abraha M. Satisfaction of clients with the services of an outpatient pharmacy at a university hospital in northwestern Ethiopia: a cross sectional study. BMC Health Serv Res. 2015;15(1):1-8. 
16. The Flesch reading ease readability formula. http://www.readability formulas.com/flesch-reading-ease-readability-formula.php. Accessed December 10, 2020.

17. Alhojailan MI. Thematic analysis: a critical review of its process and evaluation. West East J Soc Sci. 2012;1(1):39-47.

18. Association WM. World Medical Association declaration of Helsinki. Ethical principles for medical research involving human subjects. Bull World Health Org. 2001;79(4):373.

19. Boulos MN. British internet-derived patient information on diabetes mellitus: is it readable? Diabetes Technol Ther. 2005;7(3):528-535. doi:10.1089/dia.2005.7.528

20. Munsour EE, Awaisu A, Hassali MA, Darwish S, Abdoun E. Readability and comprehensibility of patient information leaflets for antidiabetic medications in Qatar. J Pharm Techn. 2017;33(4):12 8-136. doi:10.1177/8755122517706978
21. Winterstein AG, Linden S, Lee AE, Fernandez EM, Kimberlin CL. Evaluation of consumer medication information dispensed in retail pharmacies. Arch Intern Med. 2010;170(15):1317-1324. doi:10.1001/ archinternmed.2010.263

22. Kher A, Johnson S, Griffith R, Tephly TR. Readability assessment of online patient education material on congestive heart failure. $A d v$ Prev Med. 2017;1;2017(2):117-126. doi:10.1155/2017/9780317

23. Kirk JK, Krick S, Futrell D, et al. Connecting pharmacy and literacy: the North Carolina medication information literacy project. Am J Pharm Educ. 2000;64(3):277-282.

24. Koo MM, Krass I, Aslani P. Factors influencing consumer use of written drug information. Ann Pharmacother. 2003;37(2):259-267. doi:10.1177/106002800303700218

\section{Publish your work in this journal}

Patient Preference and Adherence is an international, peer-reviewed, open access journal that focusing on the growing importance of patient preference and adherence throughout the therapeutic continuum. Patient satisfaction, acceptability, quality of life, compliance, persistence and their role in developing new therapeutic modalities and compounds to optimize clinical outcomes for existing disease states are major areas of interest for the journal. This journal has been accepted for indexing on PubMed Central. The manuscript management system is completely online and includes a very quick and fair peer-review system, which is all easy to use. Visit http:// www.dovepress.com/testimonials.php to read real quotes from published authors. 